\title{
Qual caminho seguir? O dilema de uma graduanda em Administração
}

\section{Which Way To Follow? The Dilemma Of A Graduate In Administration}

\author{
GRASIELE CABRAL PEREIRA* \\ ANA PAULA PEREIRA DOS PASSOS** \\ HELENA WOLLINGER***
}

\section{RESUMO}

A indecisão sobre o caminho a seguir após a graduação é uma circunstância vivenciada por grande parte dos estudantes do curso de Administração. O curso oferece um imenso leque de possibilidades para atuação no mercado de trabalho. O estudante pode trabalhar em diferentes áreas da gestão, em organizações públicas, privadas e do terceiro setor, assim como pode abrir seu próprio negócio. O presente caso de ensino apresenta o dilema vivenciado por Roberta, uma estudante do sétimo período de Administração, que visualiza quatro diferentes caminhos para seu futuro, e se vê indecisa sobre qual escolher. As opções dispostas a Roberta são bem distintas e ela precisa decidir o que fazer, pois sua graduação está finalizando. Desse modo, a proposta deste caso é fazer com que os estudantes se coloquem no lugar de Roberta, a fim de promover um debate sobre gestão de carreira, motivação e satisfação, que os levem a se identificar com uma das opções apresentadas. Este caso pode ser usado em disciplinas de Administração de Recursos Humanos, Comportamento Humano nas Organizações e outras que trabalhem com as temáticas exploradas.

Palavras-chave: Graduação. Gestão de Carreira. Motivação. Satisfação.

* Universidade do Vale do Itajaí. Graduada em Administração. grasicp@hotmail.com ,

** Universidade do Vale do Itajaí. Mestranda em Administração. ana.passos@edu.univali.br .

*** Universidade do Vale do Itajaí. Doutoranda em Administração.

helena_wollinger@hotmail.com 


\section{Abstract}

The indecision about the path to follow after graduation is a circumstance experienced by most of the students of the Administration course. The course offers a wide range of possibilities for acting in the job market. The student can work in different areas of management, public, private and third sector organizations, as well as can open their own business. The present teaching case presents the dilemma experienced by Roberta, a student of the seventh administration period, who sees four different paths to her future, and is uncertain about which to choose. The options available to Roberta are very different, and she has to decide what to do, because your graduation is ending. Thus, the proposal of this case is to get students to take Roberta's place in order to promote a debate about career management, motivation and satisfaction, that leads them to identify with one of the options presented. This case can be used in disciplines of Human Resources Administration, Human Behavior in Organizations and others that work with the themes explored.

Keywords: Graduation. Career Management. Motivation. Satisfaction.

\section{INTRODUÇão}

Em uma noite fria, Roberta se encontrava pensativa, já passava das 2 horas da manhã e nada de o sono aparecer. Ela levantou, foi até a cozinha, preparou um chocolate quente e aproveitou para refletir sobre seu futuro. O tempo limite para tomar sua decisão estava se aproximando, e por se tratar de um dilema que definiria sua atuação profissional, Roberta tinha que analisar muito bem qual caminho escolher. Aflita por ter pouco tempo para tomar essa decisão, Roberta começou a andar de um lado para o outro e falar sozinha sobre suas possibilidades, e por conta do barulho acordou sua mãe.

- Roberta, o que você está fazendo acordada a essa hora? indagou Márcia.

- Mãe, não consigo dormir. Estou muito preocupada sobre o que devo fazer, e tenho muito medo de escolher algo que me arrependa no futuro. - explanou Roberta.

- Filha, a essa hora você não conseguirá decidir, você sabe que deve pensar com calma e escolher aquilo que te passa maior segurança. - respondeu Márcia. 
- Mas que eu devo fazer? Eu preciso de ajuda, é meu futuro que está em jogo! - Márcia sem saber o que responder, deixou a filha desabafar.

- Eu sei que seria ótimo ter um mestrado com a minha idade, mas será que o mercado de trabalho pensa da mesma maneira? Pois caso eu não queira seguir a carreira acadêmica, será que as empresas não veem uma pessoa que possui mestrado como algo muito "caro"? Mas se eu for diretamente para o mercado de trabalho, será que eu conseguiria um bom emprego e um bom cargo? Ainda tenho a opção de fazer concurso público, mas não sei se estou preparada para isso, sei que a concorrência é grande, e no momento não tenho tanto tempo para estudar, ainda estou fazendo meu TCC. E a loja, sinceramente não sei se daria certo trabalharmos juntas. - disse Roberta apreensiva.

Márcia preocupada com a situação de angústia e ansiedade de sua filha, rapidamente respondeu:

- Mas filha, ficar acordada a madrugada inteira não irá lhe ajudar. Você deveria ir dormir e descansar, pois já te falei inúmeras vezes que mente cansada não trabalha como deveria.

Roberta sem seguir o conselho de sua mãe, foi para o quarto e continuou acordada pensando sobre as alternativas que possuía. Qual das opções ela deveria escolher? Fazer um mestrado e seguir a carreira acadêmica? Ir para o mercado de trabalho e procurar por uma empresa privada? Estudar para concursos, com o objetivo de ingressar em uma organização pública? Ou abrir seu próprio negócio e tornar-se empresária?

\section{AnTECEDEnTES}

Roberta era uma criança ativa, gostava de brincar, ler e estudar, fato que a diferenciava das demais crianças. Ela sempre morou no mesmo bairro, localizado no munícipio de Governador Celso Ramos, em Santa Catarina, próximo aos seus familiares, e por conta disso, possuía um vínculo sentimental muito forte com os mesmos.

Márcia sempre incentivou a filha nos estudos, comprava livros e gibis para que Roberta despertasse o gosto pela leitura, e assim aos 7 anos, ela já havia lido inúmeros destes. Márcia trabalhava em uma farmácia, localizada no município vizinho, em Biguaçu, Santa 
Catarina. Possuía o ensino médio, e por não ter tido a oportunidade de dar continuidade aos estudos, buscou sempre estimular Roberta para que a mesma gostasse de estudar e realizasse um curso de graduação.

A mãe de Roberta, sempre ajudou sua filha, passava noites em claro auxiliando na realização de trabalhos e tarefas das disciplinas, para que Roberta se destacasse e possuísse boas notas, fato considerado importantíssimo para Márcia. Ela possuía uma postura mais rígida do que seu esposo Cláudio, não aceitando que sua filha apresentasse notas inferiores a 8, exigia que seu boletim escolar constasse ao menos um 10 a cada bimestre.

Cláudio, pai de Roberta, trabalhava em uma organização de serviços de transportes há quase dez anos. Por não possuir o ensino fundamental completo, iniciou na organização como auxiliar geral, e com as oportunidades oferecidas pela empresa, tornou-se mecânico e responsável por uma equipe de auxiliares. Cláudio era flexível e carinhoso com sua filha, buscando sempre ajudá-la a lidar com as exigências e o gênio forte de Márcia.

Márcia realizava provas mensais com Roberta, para verificar se a mesma estava absorvendo o conteúdo aprendido nas aulas. Em uma dessas provas, Roberta não soube responder a uma equação de multiplicação, e Márcia impaciente, como punição a mandou para o quarto de castigo. Cláudio ao se deparar com essa situação, lembrou de um brinquedo que ensinava a tabuada, era uma espécie de casinha, que mostrava a equação em um botão, e ao apertar este botão, a resposta acendia. Sem pensar, Cláudio saiu a procura deste brinquedo para sua filha. Assim que encontrou o brinquedo, logo comprou, e ao chegar em casa, o mesmo se colocou de castigo e passou a tarde estudando com sua querida filha.

Por mais que fosse incentivada, Roberta gostava de ir à escola desde a época do ensino primário. Ela sempre foi uma excelente aluna, participava de todos os eventos escolares, destacando-se na maioria destes. Roberta procurava encerrar suas tarefas em sala de aula mais rápido que seus amigos, para conseguir ajudá-los a fazer. Era de sua personalidade ajudar os outros e ser líder, e de fato, a mesma foi líder de classe inúmeras vezes no decorrer de sua vida acadêmica. 
Quando Roberta estava no quarto ano do ensino fundamental, Márcia foi chamada pela diretora da escola para conversar a respeito de uma atitude de sua filha em sala de aula. A professora de geografia estava ensinando sobre o sistema solar, e afirmando que o mesmo era constituído por nove planetas, e ao ouvir isso, Roberta corrigiu a professora, dizendo que esta afirmação estava errada, pois recentemente o sistema solar passou a ser constituído por oito planetas, Plutão não era mais considerado um planeta. A professora constrangida por não ter conhecimento sobre essa notícia, e por ser tratar de uma criança que estava corrigindo-a, não apresentou certa importância e deu continuidade à aula.

No dia seguinte, Roberta inconformada com essa situação, levou a revista que havia lido sobre o sistema solar, para provar que a informação que a professora estava passando era obsoleta. Aborrecida com o acontecido, a professora encaminhou Roberta para a diretoria, pois via como se ela estivesse desafiando-a.

Márcia por conhecer sua filha, sabia que as intenções da mesma eram boas, e que ela só queria alertar a professora para que não passasse informações incorretas. Sendo assim, conversou com a diretora, juntamente com Roberta, e para que essa situação não se repetisse em sala de aula, pediu que quando Roberta visse alguma divergência nas informações, que conversasse com a professora, antes de falar na frente de toda a classe. E assim foi feito, sempre que Roberta discordava de algo, conversava em particular com a professora para entender o porquê de tal informação ou dado ser daquela maneira.

Roberta estudou do ensino primário até o quarto ano do ensino fundamental nas escolas próximas de sua casa. No quinto ano do ensino fundamental ela foi transferida para outra escola, pois sua mãe, Márcia, acreditava que a escola do município vizinho oferecia um ensino melhor. Roberta, no entanto, não se adaptou, estava deprimida e não conseguiu fazer novas amizades.

A diretora da escola ligava para Márcia frequentemente, informando que Roberta estava chorando e pedindo para ser transferida para a escola que seus amigos estavam estudando. Então, Márcia decidiu transferir e nesta nova escola Roberta completou o ensino fundamental e o ensino médio. 
Passaram-se os anos e Roberta manteve o mesmo perfil, ajudava seus amigos nas tarefas e os auxiliava nos estudos de química, física e matemática, disciplinas em que possuíam mais dificuldades. Ela adorava esses assuntos que necessitavam de raciocínio quantitativo.

A escola em que estudava era pública e não possuía recursos suficientes para investir em materiais e preparações para as provas de vestibular. Dessa maneira, Roberta passou a estudar sozinha, se preparando para a realização de tais provas.

No ano de 2013, Roberta optou por não fazer os vestibulares das universidades públicas da região, e realizar apenas a prova do Exame Nacional de Ensino Médio (ENEM), no intuito de ingressar em uma universidade privada no curso de engenharia química. Ela não se sentia preparada para os vestibulares, mas tinha ciência que seus pais não teriam condições de pagar um curso de graduação. Sendo assim, a prova do ENEM poderia possibilitar a Roberta uma bolsa integral de estudos.

Após concluir o ensino médio, Roberta começou a trabalhar em uma pequena fábrica de cúpulas de abajur, próximo a sua residência. Ao se deparar com a má gestão da organização, e com vontade e ideias para ajudar esta empresa, Roberta percebeu que desde pequena possuía o dom para liderar, gerenciar, e controlar as pessoas e as situações. Neste momento, viu que a carreira certa a seguir seria a de administradora.

Roberta havia se inscrito para um curso comunitário preparatório para o vestibular, no qual conseguiu uma vaga em fevereiro do ano seguinte ao término do ensino médio. O curso ocorria na capital do estado, e para chegar até o mesmo Roberta teria que sair de casa às $16 \mathrm{~h}$, pois morava longe e o curso iniciava às $18 \mathrm{~h}$, porém este horário se chocava com a sua jornada de trabalho, na qual iniciava às $7 \mathrm{~h}$ e encerrava às $18 \mathrm{~h}$. Sendo assim, ela teve que tomar uma decisão muito importante: largar seu emprego, no qual utilizava o salário para ajudar seus pais nas despesas de casa, ou deixar o curso e o sonho de entrar em uma universidade para depois?

Após pensar muito, e conversar com seus pais, Roberta decidiu entrar no curso preparatório. Neste período, ela realizou a inscrição para uma bolsa de estudos na universidade privada no município vizinho. Em julho de 2014, Roberta recebeu um e-mail informando 
que havia conseguido a bolsa de estudos em Administração na Universidade do Vale do Itajaí, no munícipio de Biguaçu.

Roberta encontrava-se muito contente, pois além de ser o curso desejado, ela estudaria próximo de casa, e estaria próxima a sua família, algo considerado importantíssimo por ela. As aulas iniciariam em agosto e Roberta contava os dias para o início do semestre letivo.

\section{A GRADUAÇÃo EM AdMINISTRAÇÃo}

Logo na primeira semana de aula, Roberta já possuía muitos colegas e a cada aula que passava se sentia mais entusiasmada com o curso. No decorrer da graduação, Roberta teve uma variedade de disciplinas que abordavam diferentes temas, tratando-se desde a gestão de pessoas à administração financeira das organizações.

Roberta se identificava bastante com as disciplinas de Recursos Humanos, assim como as que envolviam cálculos e processos de gestão das organizações, como a Administração da Produção e Operações, Administração Financeira e Gestão Empresarial. Ela sempre teve facilidade para lidar com pessoas e gostava muito da parte lógica das organizações, ansiava trabalhar em uma destas áreas.

Roberta sabia que durante a graduação, a instituição de ensino superior proporcionava aos seus alunos conhecimento teórico sobre todas as áreas da Administração, mas não contemplava o conhecimento técnico, o que dificultava a inserção no mercado de trabalho para recém graduados. Grande parte das organizações privadas requeriam de seus candidatos ao menos um ano de experiência registrada na carteira de trabalho para cargos administrativos. Desse modo, Roberta apesar de não saber ainda em que área gostaria de trabalhar, começou a buscar por estágios para identificar a realidade das organizações públicas e privadas.

No primeiro semestre na universidade, ela conseguiu um estágio na empresa $X$ em Florianópolis, na área financeira. Roberta realizava funções administrativas, suas principais atribuições eram lançamento de notas fiscais, fechamento de caixa, controle de estoque, conciliação bancária, baixa no sistema de controle bancário, controle de contas a pagar, controle dos recebimentos da empresa, emissão de relatórios, arquivamento de documentos, alimentação de planilhas, faturamento de clientes e atendimento. 
A sala em que ela trabalhava ficava próxima a dos gestores da empresa e assim teve a oportunidade de adquirir experiência de como funcionava uma grande organização. Ela observou como os gestores se comportavam e quais atitudes e habilidades eram necessárias para alcançar tal cargo. Quatro meses após a sua entrada na empresa $X$, surgiu uma vaga para realizar um estágio em uma organização pública.

Com a busca crescente de conhecimento, Roberta viu nesta situação a oportunidade de compreender como funcionava uma organização pública, no qual ela acreditava ser totalmente diferente de uma privada. Assim, ela decidiu pedir demissão do estágio na empresa $\mathrm{X}$ e iniciar na empresa $\mathrm{Z}$.

O novo estágio era mais próximo de sua casa, localizado no centro de Biguaçu. As funções desempenhadas por Roberta eram totalmente diferentes do estágio anterior. Ela auxiliava as pessoas no setor de autoatendimento, possuindo assim contato direto com o público, realizava o arquivamento de documentos e auxiliava seu gerente na retirada de senhas para o atendimento no interior da empresa.

Como Roberta esperava, a gestão de uma organização pública era diferente da empresa privada, mas não tão diferente quanto imaginava. Pois, pôde observar que assim como os colaboradores da empresa $X$ tinham metas a cumprir, os da empresa $Z$ também possuíam.

Roberta gostava de trabalhar na empresa Z, conseguia atender aos clientes com eficácia e era sempre elogiada por seu chefe, e alguns clientes gostavam tanto dela, que em datas comemorativas, como Natal e Páscoa, levavam lembrancinhas, mostrando como se importavam e a adoravam.

Em março de 2016, quando Roberta estava no quinto período do curso, uma colega da universidade, por conhecer o perfil dela, a indicou para um projeto de iniciação científica, orientado pelo professor Augusto. Assim, sem pensar duas vezes, Roberta se inscreveu para participar do processo seletivo do projeto. E uma semana após sua entrevista, recebeu um e-mail informando que havia conseguido a vaga.

Roberta estava há 1 ano e 4 meses no estágio da empresa Z, já tinha conhecimento sobre o funcionamento de uma organização 
pública, e visando se dedicar somente ao projeto de iniciação cientifica, pediu demissão do estágio.

No decorrer do projeto, Roberta despertou um grande interesse pela pesquisa, se identificou com a iniciação científica. Este projeto lhe proporcionou novos conhecimentos, ela passou a ler artigos científicos, o que acarretou uma melhora da sua escrita e uma expansão do seu vocabulário.

Na iniciação científica, Roberta passou a ter mais contato com o Programa de Pós-Graduação em Administração da Universidade, tendo contato direto com a mestranda Amanda, que também era orientada por Augusto. Amanda sempre contava a Roberta sobre os conhecimentos adquiridos durante o curso de mestrado e a cada conversa, ela tinha mais interesse no curso. Roberta desde criança gostava de ensinar os outros, e com o mestrado, poderia dar início a uma carreira acadêmica.

Depois de experiências tão distintas, no sétimo período, quase no fim da graduação, Roberta estava muito indecisa em qual rumo tomar, não sabia se deveria ir para o mercado de trabalho ou continuar sua formação em um curso de mestrado.

\section{UM POUCO MAIS DE SUA VIDA PROFISSIONAL}

Os estágios possibilitaram experiências interessantes para Roberta, tanta na empresa privada como na pública. Ela pôde compreender como estas funcionavam e quais eram as habilidades e atitudes necessárias para trabalhar em cargos altos em ambas as organizações.

Por observar a desmotivação dos colaboradores na organização pública em que atuou, Roberta se imaginava em um cargo na área da gestão, realizando atividades que fizessem com que os colaboradores se sentissem mais motivados. Ela percebeu que apesar dos funcionários públicos possuírem estabilidade em seu emprego e geralmente salários superiores a colaboradores de empresa privada, há um descontentamento, talvez pela acomodação e estagnação profissional causada por esta estabilidade, ou pela monotonia dos serviços realizados e dificuldade na sucessão para cargos melhores.

Nas organizações públicas, um indivíduo só pode ser promovido a seu nível de formação, ou seja, se Roberta prestasse concurso 
público antes do término da graduação, teria que fazê-lo para ensino médio, o que dificultaria o seu alcance a um cargo gerencial e a deixaria insatisfeita.

Roberta teve a oportunidade de trabalhar em uma pequena e uma grande empresa privada. Na pequena empresa, ela pôde observar que os gestores da organização eram os próprios proprietários e que grande parte dos colaboradores eram familiares ou conhecidos. Ela sabia que empresas desse porte, raramente teriam uma gestora de Recursos Humanos, ou até mesmo de Finanças, pois não possuíam recursos e até mesmo colaboradores suficientes para tais áreas.

Já na grande empresa, Roberta teve uma experiência totalmente diferente. Os cargos gerenciais eram todos ocupados por gestores que não possuíam nenhum vínculo familiar com os proprietários da organização, mas todos possuíam faixa etária superior a 40 anos e estavam há mais de 15 anos na empresa. Ela acreditava que isto resultava da dificuldade em alcançar cargos que necessitavam de maior responsabilidade, pois por possuírem mais liberdade na tomada de decisão, estes cargos eram mais demorados para se alcançar.

A empresa privada em que trabalhou, possuía um plano de cargos e salários, deste modo, era necessário iniciar como auxiliar administrativo, e pelo que observou demoraria um tempo para que alcançasse um cargo gerencial, fato que não a deixa tão motivada, pois queria iniciar em um cargo em que pudesse ajudar aos outros e a própria organização, Roberta queria tomar decisões importantes. Mas a competitividade no mercado era grande, outro fator a ser pensado por ela.

\section{EMPREENDER? TALVEZ.}

Em uma noite de sexta feira, Márcia chegou em casa cansada e desgastada pela extensa rotina de trabalho e pela falta de reconhecimento em seu emprego, viu-se desmotivada para ir trabalhar no outro dia e desabafou com Roberta:

- Filha, não estou aguentando mais, pois sempre faço o meu melhor, me dedico inteiramente ao meu serviço e nunca sou reconhecida. - Márcia começou a chorar, e Roberta sem entender muito o que estava acontecendo perguntou:

- Mas o que aconteceu mãe? Por que a senhora está assim? 
Márcia contou para a filha que surgiu uma vaga em seu emprego para tesoureira, e que todos acreditavam que ela seria indicada, pois estava há bastante tempo na organização e possuía uma vasta experiência sobre todas as tarefas que deveriam ser realizadas. O que ela não esperava era que sua colega fosse indicada em seu lugar.

Márcia ainda disse que ficou extremamente chateada, pois sua gestora já havia falado que quando surgisse tal vaga, ela seria a primeira escolha. Este ocorrido foi no começo da semana, e Márcia explicou a filha que desde aquele dia, a colega que ocupou o cargo, começou a tratá-la com desprezo e superioridade.

Roberta ficou indignada, e começou a pensar nas possibilidades que sua mãe tinha. Ela sabia que Márcia não poderia ficar desempregada, pois a família precisava da renda dela para sobreviver. Roberta estava ciente que o mercado de trabalho estava cada vez mais competitivo, e que sua mãe só possuía experiência de caixa e atendente na farmácia, e então provavelmente conseguiria um emprego nessas áreas. Ela também sabia que sua mãe estava cansada destes serviços, e que por causa destes, estava com um grave problema de tendinite nos ombros e no punho.

Roberta ficou dias analisando as vagas de emprego, e viu que aquilo não era o que Márcia precisava no momento. Até que Roberta teve a ideia de sua mãe abrir um negócio próprio. Por fazer graduação em Administração, ela conhecia basicamente todos os processos a serem realizados para a abertura de um empreendimento, e sabia que há um investimento inicial a ser feito.

Roberta conversou com sua mãe, sobre a possibilidade de ela abrir um negócio próprio, e explicou que no início ela necessitaria realizar um investimento. Márcia interrompeu a explicação de sua filha e disse:

- Filha, eu e seu pai ao longo dos anos guardamos uma quantia no banco, para que se surgisse um imprevisto, nós tivéssemos um valor de "garantia".

- Ótimo, mãe! Eu estava pensando que você precisaria solicitar um empréstimo no banco, o que poderia dificultar um pouco o início de seu negócio. - disse Roberta.

- Mas o que poderíamos abrir? Não faço a mínima ideia no que empreender. - relatou Márcia. 
- Mãe, eu estava pensando em abrir uma loja de roupas em Biguaçu. Tenho duas colegas na universidade que abriram sua própria loja e estão muito bem no mercado. E como a senhora possui um bom networking por ter trabalhado anos na região, e por frequentar os salões de beleza, acho que seria uma boa escolha.

Márcia ficou muito empolgada com a sugestão da filha, e por sempre ter gostado muito de roupas e moda, imediatamente aceitou a proposta de Roberta sobre a abertura de uma loja de roupas. Roberta já havia pensando até na localização da loja, e explicou para sua mãe:

- Lembra aquela minha colega que possui pontos comerciais bem no centro da cidade? Ela me disse essa semana que estavam com uma sala vaga, pois a loja de suplementos que havia no local, se mudou para mais perto da academia. Estava pensando em conversamos com ela, para que alugassem para senhora.

- Lembro sim, é um ótimo local. E por se tratar de uma sala no centro da cidade, eu sei que passa um grande fluxo de pessoas diariamente. - disse Márcia.

Assim, Roberta começou a pesquisar especificamente sobre o que seria necessário para a abertura de uma loja de roupas. Foram dias de pesquisa, Roberta chegou a pedir ajuda para alguns professores na universidade.

Três semanas após o desabafo de sua mãe, Roberta a chamou para conversar e apresentou todos os dados e informações coletadas sobre a abertura de uma loja varejista de roupa. Roberta explicou para sua mãe, que comparado a outras organizações, o investimento inicial para a abertura da loja seria relativamente baixo, pois os fornecedores que havia entrado em contato, disponibilizavam uma carência para o pagamento das mercadorias, então inicialmente Márcia teria que investir para o pagamento do aluguel de um espaço, para os móveis e reformas a serem realizadas.

Márcia muito entusiasmada, ligou para Cláudio para contar sobre a proposta da filha. O pai de Roberta não sabia do que havia acontecido com Márcia anteriormente, e para explicar o porquê de tal proposta as duas contaram a história para ele, o mesmo ficou transtornado e furioso com a traição que a colega de sua esposa tinha lhe causado. 
Após contar todo o acorrido, Roberta explicou a seu pai os processos, as documentações necessárias, e o que teriam que fazer para iniciar o empreendimento. Adiantada, ela explicou que já havia entrado em contato com diversos fornecedores, que sua mãe conseguiria um prazo de carência para o pagamento dos produtos, e que alguns destes inicialmente disponibilizavam até dois manequins para a loja poder colocar em sua vitrine.

Cláudio se sentiu confiante com a proposta da filha, ofereceu bastante apoio a sua esposa, e disse para ela sair do atual emprego e iniciar em seu negócio próprio. O que Roberta não esperava, era que seu pai a pedisse para auxiliar sua mãe na loja, pois ele sabia que Márcia não daria conta sozinha.

- Filha, você precisa encarar essa mudança com sua mãe. Você sabe que ela não possui o seu conhecimento e que terá dificuldades na gestão da loja. - disse Cláudio.

Roberta sem saber o que responder, disse ao seu pai:

- Há muito o que analisar ainda, se preocupe com isso depois. - salientou Roberta e mudou rapidamente de foco na conversa.

Roberta se sentiu pressionada, pois queria ajudar sua mãe em seu negócio próprio, e possuía o conhecimento necessário para a abertura de um empreendimento, mas ficou com receio, pois este era um caminho a ser seguido, ainda não imaginado por ela.

O que deveria fazer? Essa era a resposta que Roberta não tinha naquele momento.

\section{QUAL CAMINHO SEGUIR?}

Roberta estava indecisa, tinha dúvidas sobre qual caminho lhe proporcionaria mais satisfação profissional. Ela se via frente a quatro direções, a primeira seria atuar em uma empresa privada de médio ou grande porte. No entanto, para tal ainda precisaria definir em qual área da administração gostaria de trabalhar, que era mais uma dúvida que lhe rodeava.

Santa Catarina é um dos estados mais ricos do país, e a região da Grande Florianópolis representa 14,1\% do PIB do estado, de acordo com dados do IBGE. A região tem uma economia diversificada destacando-se nos setores de tecnologia, turismo, serviços e construção civil. 
Havia muitas empresas privadas na região da Grande Florianópolis, principalmente de pequeno e médio porte. Mas a região também é sede de grandes empresas, em Florianópolis, localiza-se 13 das 500 empresas da lista "Maiores do Sul - Grandes\&Líderes", ranking divulgado em 2014. Nestas empresas de grande porte, Roberta sabia que inicialmente iria trabalhar na área operacional. Além disso, a disputa pelas vagas era grande, havia muitos cursos de administração na cidade e o número de formandos por ano era considerável, ela precisaria se destacar para ser selecionada.

Ainda, nessas empresas era comum a solicitação de inglês intermediário e Roberta tinha apenas o básico aprendido no ensino médio. Desse modo, ela possuía um pouco de receio, mas estava participando ativamente dos processos seletivos e apresentando seu melhor.

Outro dilema que Roberta via a frente era a falta de experiência comprovada em carteira, ela durante os anos de graduação, realizou apenas estágios, os quais eram firmados por contratos, e a maioria das empresas contratantes solicitava um ano de experiência comprovada em carteira na área administrativa. Diante dessa realidade, Roberta pensava:

"não sei se eu seria uma pessoa satisfeita em trabalhar na área operacional em uma empresa privada. Quero ajudar aos outros, poder aplicar meu conhecimento, e sei que será quase impossível iniciar em um cargo que me possibilite isto".Seu segundo caminho era a empresa pública, tão almejada pelos seus colegas de classe, pois possuía bons salários e estabilidade, mas será que isso a satisfaria? O município de Florianópolis, capital de Santa Catarina, era vizinho da cidade em que Roberta residia, assim o número de órgãos públicos próximos era relativamente alto, se comparado a outras cidades do estado. Porém, Roberta refletia:

"não descarto a possibilidade de trabalhar em uma organização pública, mas sei que para isso teria que me dedicar exclusivamente aos estudos, pois sei que as vagas são bem concorridas, mas e se eu ficasse anos estudando e não passasse?". Além disso, para estudar exclusivamente para concursos ela teria que ficar longe do mercado de trabalho, e várias perguntas a rodeavam: 
Será que valeria a pena ficar sem rendimentos para me dedicar a estudar para concursos? Mas, e se eu trabalhasse e estudasse? Não sei se daria certo, pois em uma empresa privada normalmente serão oito horas diárias de trabalho, será que me manteria motivada?

O terceiro caminho visualizado por Roberta era o Mestrado, ela adorava estudar e compartilhar informações, o curso lhe propiciaria isso, além de futuramente poder dar aulas e atuar na área da pesquisa. Para sua formação, a região contava com cinco programas de Mestrado, e de acordo com dados da plataforma lattes, em 2016, 1.060 mestres se formaram na no estado de Santa Catarina área de administração. Já no que tange sua atuação futura, os municípios próximos de Governador Celso Ramos contavam com muitos centros universitários, faculdades, institutos e escolas técnicas.

Mas novamente teria que ficar sem rendimentos. Roberta já havia se informado e as aulas do Mestrado ocorriam em período vespertino e/ou matutino, e assim, poucas empresas a liberariam em horário de expediente para a realização do curso.

Tanto em relação a sua dedicação aos concursos como referente ao mestrado havia a barreira financeira, precisaria se organizar para tomar umas das decisões ou buscar outras fontes de recursos, no caso do mestrado poderia, por exemplo, tentar uma bolsa.

E ainda tinha a abertura do seu próprio negócio, mas valia a pena arriscar? Será que estava preparada? Era um desafio, e Roberta adorava desafios, mas não sabia se era isso que queria, pois teria que trabalhar com sua mãe na loja. Ela gostaria de gerir uma empresa, claro, mas tinha o receio dos pensamentos controversos que ela e sua mãe possuíam, será que daria certo? E se investirem e não gerar o lucro esperado, teriam ambas que retornar ao mercado para estabilizar financeiramente a família.

Os dias se passaram, Roberta já estava terminando o sétimo período da graduação, e ela ainda estava indecisa sobre qual rumo tomar. Roberta não tinha mais tempo para pensar, a decisão teria que ser tomada já, mas qual das opções escolher? Fazer um mestrado e seguir carreira acadêmica? Ir para o mercado de trabalho e procurar por uma empresa privada? Estudar para concursos, com o objetivo de ingressar em uma instituição pública? Ou abrir seu negócio e tornar-se empresária? 


\section{NOTAS DE ENSINO}

\section{Fontes de informações}

As informações utilizadas para a construção deste caso de ensino foram obtidas de fontes primárias e secundárias. As informações primárias foram adquiridas por meio de entrevistas realizadas com a personagem principal. As informações secundárias incluíram websites do governo de Santa Catarina, do Instituto Brasileiro de Geografia e Estatística, da plataforma lattes e outros websites jornalísticos. Essas informações secundárias foram necessárias para a apresentação da realidade econômica do estado de Santa Catarina. Os nomes dos personagens e a narrativa são fictícias, a fim de preservar suas identidades.

\section{Objetivos educacionais e utilização recomendada}

O presente caso foi desenvolvido para proporcionar uma discussão sobre a importância da gestão de carreira, dos fatores motivacionais, da satisfação profissional e das âncoras de carreiras. Bem como, incitar a reflexão de como esses elementos influenciam as decisões profissionais dos indivíduos.

A discussão será realizada por meio da identificação com o problema, ou seja, os estudantes se colocarão no lugar de Roberta e analisarão seu perfil, seus anseios, suas motivações e suas âncoras. $\mathrm{O}$ estudante, ainda verificará cada uma das possibilidades apresentadas no caso, em contraste com as informações apresentadas sobre Roberta.

Os alunos devem ser capazes de desenhar os diferentes cenários profissionais para Roberta e identificar os riscos de cada decisão. Para assim, definirem a alternativa mais viável para a solução do dilema.

Espera-se que os alunos, por meio do caso, desenvolvam uma compreensão do conceito de motivação, para tanto, será discutido os fatores motivacionais de Roberta. Também se almeja que o entendimento do conceito de gestão de carreira, mais especificamente, a importância da manutenção da empregabilidade e da reflexão sobre suas âncoras de carreira e motivações para as definições profissionais.

Anseia-se também que os alunos após discutir sobre o dilema de Roberta, se identifiquem com a personagem e reflitam sobre sua própria realidade e sobre planos para sua própria carreira profis- 
sional. Espera-se que o presente caso incite a disposição dos alunos para analisar suas motivações, vida profissional e para planejar o seu futuro.

Resumidamente, os objetivos do caso são: a) compreender os conceitos de motivação, satisfação, âncoras de carreira, empregabilidade e gestão de carreira; b) identificar no dilema de Roberta e na sua história a relação com tais teorias; c) analisar criticamente o alinhamento dos conceitos de motivação, satisfação, âncoras de carreira e empregabilidade com o conceito de gestão de carreira; d) e refletir sobre as opções de Roberta e seus riscos.

Este caso de ensino é recomendado para os cursos de Graduação em Administração, em disciplinas de Administração de Recursos Humanos, Comportamento Humano nas Organizações e outras disciplinas que trabalhem com as temáticas exploradas no caso.

\section{Plano de aula}

Para a discussão do presente caso de ensino, sugere-se a preparação individual e prévia dos alunos. O professor pode disponibilizar o caso com uma semana de antecedência para leitura. Considerando a aprendizagem indutiva, não se faz necessário a leitura prévia de conceitos teóricos. No entanto, se o professor preferir fornecer textos complementares, indica-se os artigos presentes na bibliografia recomendada.

Para a aula de aplicação, propõe-se que o professor inicie a discussão estimulando a reflexão sobre o dilema do caso. Após ouvir as opiniões iniciais dos alunos, o professor deve entregar a lista de questões sugeridas para a discussão e solicitar que os alunos formem grupos. O debate em minigrupos deve ser realizado sobre as três primeiras questões. Os alunos devem listar as ideias e opiniões do grupo e as divergências, para uma discussão posterior com toda a turma.

Ao finalizar a discussão nos minigrupos, sugere-se que o professor forme uma mesa-redonda com toda a turma. Na discussão no grande grupo, o professor pode ler cada questão individualmente (questões 1, 2 e 3), e solicitar que cada grupo apresente oralmente a sua análise sobre aquela questão. Durante a apresentação dos grupos, o professor deve mediar o debate e questionar sobre os 
achados dos grupos. Bem como, em conjunto com os alunos, ele deve construir as conexões teóricas, que emergiram durante a análise.

Na última questão, propõe-se que o professor divida a turma em quatro grupos, sendo cada um responsável por defender uma ideia referente o dilema principal do caso. Cada grupo também deve apresentar um plano para a gestão de carreira de Roberta. O grupo A deve abordar a realização do mestrado, o grupo B o mercado de trabalho, o grupo $\mathrm{C}$ o concurso público, e por fim, o grupo D, defenderá a ideia de Roberta se tornar empresária.

O professor deve criar na discussão desta questão, um jogo, em que o debate entre os grupos ocorrerá em uma plenária. Cada um dos grupos deverá ter argumentos para convencer os integrantes dos outros grupos que sua alternativa é a melhor solução para Roberta. Deste modo, além de identificar as características positivas relacionadas a sua decisão, os alunos precisam verificar os riscos e como podem melhor se preparar para amenizar os mesmos.

Durante a plenária, o professor deve estimular os grupos a questionarem os argumentos dos outros grupos. O professor também deve dividir a lousa em quatro partes e escrever os pontos fortes e fracos de cada alternativa, que foram evidenciados pelos grupos durante a discussão. Desse modo, tornará mais visível a todos os argumentos levantados, norteando melhor o debate.

Por fim, o professor pode finalizar a aula informando que não há uma resposta certa e que Roberta poderia optar por qualquer uma delas.

\section{SUGESTÕeS DE QUESTõeS PARA DISCUSSÃo}

Questão 1. Quais fatores motivacionais são considerados importantes por Roberta? Questão 2. Quais âncoras de carreia se percebe em Roberta a partir das características descritas no caso? Questão 3. Quais fatores de empregabilidade Roberta possui e quais precisa desenvolver para seguir os caminhos apresentados no caso? Questão 4. Se você fosse Roberta, qual caminho seguiria? A partir dessa escolha trace o plano de carreira.

\section{ANÁlise do CASo Com SUPORTE Da literatura}

Questão 1. Quais fatores motivacionais são considerados importantes por Roberta?

A primeira questão tem como objetivo a discussão sobre fatores motivacionais e sua influência na gestão da carreira. Assim, é impor- 
tante que os alunos compreendam o que é motivação e identifiquem no caso trechos que apresentem os fatores que são importantes para Roberta. Vale destacar para os alunos, que cada indivíduo possui maneiras distintas de ser motivado e de se sentir motivado, não há qualquer tipo de padrão ou domínio de fatores (BERGAMINI, 2002).Para a identificação dos fatores motivacionais e conexão com a literatura, o professor pode definir uma das teorias motivacionais ou trabalhar com mais de uma teoria simultaneamente. Para esta análise definiu-se a teoria da hierarquia das necessidades de Maslow e a teoria das necessidades de McClelland.

Maslow (1943) propõe cinco necessidades organizadas em uma hierarquia de prepotência, quando uma das necessidades está parcialmente satisfeita surge um novo conjunto de necessidades, entretanto essa hierarquia não é fixa, apesar da maioria dos indivíduos ter as necessidades na ordem indicada, há exceções. O quadro 1 apresenta as cinco necessidades de Maslow e suas características.

Quadro 1: Hierarquia das necessidades de Maslow.

\begin{tabular}{|l|l|}
\hline Necessidade & Características \\
\hline Fisiológicas & $\begin{array}{l}\text { Ligada a fatores de sobrevivência do indivíduo, ne- } \\
\text { cessidades físicas básicas, como fome, sede e sono. }\end{array}$ \\
\hline Segurança & $\begin{array}{l}\text { Associada diretamente ao desejo de se defender } \\
\text { do perigo e ameaças, tanto para si quanto para sua } \\
\text { família. Este perigo pode ser a problemas de saúde, } \\
\text { acidentes, assim como instabilidade financeira, ou } \\
\text { seja, necessidade de sentir-se seguro e estável. }\end{array}$ \\
\hline Sociais & $\begin{array}{l}\text { Necessidade de amor, interação, convívio social, per- } \\
\text { tencimento, afeto e os vínculos de amizade. }\end{array}$ \\
\hline Estima & $\begin{array}{l}\text { Necessidade do reconhecimento das capacidades e } \\
\text { limites pessoais, e reconhecimento dos outros perante } \\
\text { a própria flexibilidade as funções que são solicitadas. } \\
\text { Visa a conquista do respeito dos outros, a autoestima. }\end{array}$ \\
\hline Auto realização & $\begin{array}{l}\text { Necessidade de ser tudo que o indivíduo é capaz de } \\
\text { ser. Fazer aquilo que é realmente desejado por ele. }\end{array}$ \\
\hline
\end{tabular}

Fonte: Maslow (1943) e Pérez-Ramos (1990). 
Percebe-se no caso de ensino, que a necessidade social de Roberta já se encontra parcialmente satisfeita, pois ela possui vínculos sociais da graduação, dos trabalhos anteriores e com familiares. Além disso, no presente caso, Roberta não manifestou interesse na busca de novos vínculos sociais.

Também verifica-se considerando a narrativa do caso, que o dilema está interligado as necessidades de segurança e estima de Roberta. Assim, entende-se que ela tem como fatores motivacionais a busca por sentir-se segura e estável em uma profissão, a estabilidade financeira, a conquista do respeito dos outros e o reconhecimento de suas capacidades.

Ainda neste contexto, vale ressaltar que Roberta não estava segura sobre algumas alternativas devido à falta de estabilidade financeira. A personagem relatou que não teria condições para arcar com os custos do Mestrado e de estudar exclusivamente para concursos públicos. Desse modo, interpreta-se que na eventualidade de optar por ser empresária juntamente com sua mãe, algumas necessidades primárias da família também precisam ser consideradas.

Ademais, destaca-se que o fato de Roberta não ter a necessidade de segurança suprida relaciona-se com sua idade e sua pouca experiência no mercado de trabalho. Porém, como observou-se no caso apesar dessa insatisfação, a necessidade por estima fica evidente, Roberta demonstra que almeja reconhecimento ao relatar que gostaria de atuar em cargos estratégicos, no qual poderia utilizar seu conhecimento teórico para colaborar com os objetivos organizacionais.

No que tange a teoria de McClelland para identificar os fatores motivacionais de Roberta, a teoria apresenta três tipos de necessidades, com diferentes grau de intensidade em cada indivíduo, conforme o quadro 2.

A partir do caso de ensino e das características apresentadas no quadro 2, pode-se verificar que a necessidade de realização se expressa em grande parte da história de Roberta, pois ela quer ter autonomia na realização de decisões, responsabilidades e desafios em seu ambiente de trabalho, além de almejar seu desenvolvimento pessoal e profissional. 
Quadro 2: Teoria de McClelland

\begin{tabular}{|l|l|}
\hline Necessidades & Características \\
\hline $\begin{array}{l}\text { Necessidade de } \\
\text { realização }\end{array}$ & $\begin{array}{l}\text { Desejo de atingir altos níveis de desenvol- } \\
\text { vimento, autonomia no desempenho e acei- } \\
\text { tação de responsabilidades no seu trabalho, } \\
\text { assumindo desafios reais. }\end{array}$ \\
\hline $\begin{array}{l}\text { Necessidade de } \\
\text { afiliação }\end{array}$ & $\begin{array}{l}\text { Desejo de desenvolver e manter um relacio- } \\
\text { namento social. }\end{array}$ \\
\hline Necessidade de poder & $\begin{array}{l}\text { Desejo de ser prestigiado, de dominar e de } \\
\text { controlar as atitudes e ações dos demais, de } \\
\text { desempenhar tarefas de liderança e influen- } \\
\text { ciar os outros. }\end{array}$ \\
\hline
\end{tabular}

Fonte: Elaborado pelos autores com base em Pérez-Ramos (1990).

Também observa-se a sua vontade de gerir, controlar e ajudar pessoas, e estas características referem-se à necessidade de poder. Já sobre a necessidade de afiliação, a mesma não encontra-se evidente no decorrer do caso de ensino. Desta forma, os fatores motivacionais de Roberta, considerando a teoria de McClelland, são os desejos relacionados a necessidade de realização e poder.

Após a identificação dos fatores motivacionais de Roberta, o professor pode sugerir que os alunos reflitam sobre suas motivações e suas necessidades atuais.

Questão 2. Quais âncoras de carreia se percebe em Roberta a partir das características descritas no caso?

A segunda questão tem por objetivo a discussão sobre as âncoras de carreira de Roberta, para tal, é interessante a compreensão inicial sobre o que são âncoras de carreira, após os alunos devem identificar quais âncoras são evidenciadas no caso.

As âncoras de carreira tiveram seu início no estudo de Edgar Schein, de 1961, em que se realizou uma pesquisa com mestrandos da Escola Sloan de Administração, na qual buscava aprimorar pesquisas relacionadas a carreiras administrativas (GOMES et al., 2011).

Destaca-se que as âncoras de um indivíduo se formam a partir da auto percepção de suas habilidades, necessidades, objetivos e valores quanto suas preferências profissionais (PEÇANHA et al., 
2011). Schein (1990) considera que o conhecimento sobre as suas preferências, faz com que as pessoas optem por alternativas mais conscientes relacionadas a sua profissão.

Baseado na sua pesquisa iniciada em 1961, e em outras efetuadas posteriormente, Schein identificou oito categorias de âncoras de carreiras que podem determinar a autoimagem dos indivíduos em relação a suas áreas de preferências (SALES; XAVIER FILHO; DAMASCENA, 2017). O quadro 3 explica de maneira sucinta as principais características de cada âncora de carreira.

Quadro 3: Âncoras de Carreiras e suas Características.

\begin{tabular}{|l|l|}
\hline Âncoras & Características \\
\hline $\begin{array}{l}\text { Competência } \\
\text { Técnica/Funcio- } \\
\text { nal }\end{array}$ & $\begin{array}{l}\text { Indivíduos que valorizam experiências profissionais que } \\
\text { desafiem sua capacidade técnica na execução das tarefas, pois } \\
\text { se sentem motivados e estimulados quando necessitam exer- } \\
\text { cer alguma aptidão especifica. }\end{array}$ \\
\hline $\begin{array}{l}\text { Competência } \\
\text { Gerência Geral }\end{array}$ & $\begin{array}{l}\text { Indivíduos que são motivados pela oportunidade de liderar } \\
\text { e tomar decisões de grande importância para a organização. } \\
\text { São conhecidos também por possuírem boa capacidade analí- } \\
\text { tica, bom relacionamento interpessoal e intergrupal, além de } \\
\text { terem equilíbrio emocional. }\end{array}$ \\
\hline $\begin{array}{l}\text { Autonomia/In- } \\
\text { dependência }\end{array}$ & $\begin{array}{l}\text { Pessoas que prezam pela sua autonomia, liberdade e inde- } \\
\text { pendência para a execução de tarefas. E possuem dificulda- } \\
\text { de para trabalhar seguindo regras, controles e padrões que } \\
\text { venham a interferir em sua independência. }\end{array}$ \\
\hline $\begin{array}{l}\text { Segurança/Esta- } \\
\text { bilidade }\end{array}$ & $\begin{array}{l}\text { Indivíduos que valorizam a estabilidade, e conduzem sua car- } \\
\text { reira profissional para organizações que transmitam segurança. }\end{array}$ \\
\hline $\begin{array}{l}\text { Criatividade } \\
\text { Empreendedora }\end{array}$ & $\begin{array}{l}\text { Pessoas que possuem originalidade e criatividade para a ela- } \\
\text { boração de novos produtos, serviços e organizações. }\end{array}$ \\
\hline $\begin{array}{l}\text { Serviço/Dedica- } \\
\text { ção a uma Causa }\end{array}$ & $\begin{array}{l}\text { O indivíduo leva em consideração seus valores pessoais para } \\
\text { realização de trabalhos profissionais, priorizando as ações que } \\
\text { auxiliem o próximo e a estruturação de uma sociedade melhor. }\end{array}$ \\
\hline Puro Desafio & $\begin{array}{l}\text { Pessoas que buscam a superação de problemas impossíveis e } \\
\text { a explicação para dilemas inexplicáveis. E estão em constante } \\
\text { mudança, buscando novas oportunidades de experiência, sem } \\
\text { medo dos desafios que isso poderá trazer. }\end{array}$ \\
\hline Estilo de Vida & $\begin{array}{l}\text { Indivíduos que procuram possuir o equilíbrio entre a sua } \\
\text { vida profissional, pessoal e familiar. }\end{array}$ \\
\hline
\end{tabular}

Fonte: Elaborado pelos autores com base em Faro et al. (2010). 
A partir do quadro, é possível identificar que Roberta apresenta algumas destas âncoras de carreiras. A principal âncora de Roberta é a de Dedicação a uma Causa, pois ela sempre deixava evidente a satisfação em ajudar ao próximo. Esta âncora pode ser observada na narrativa de forma clara, quando é mencionado o fato de que Roberta ajudava seus amigos nas tarefas e os auxiliava nos estudos de química, física e matemática, disciplinas em que possuíam mais dificuldades. Além disso, pode-se perceber esta característica quando é apresentado o sentimento de Roberta em relação a empresa privada que a mesma trabalhou, pois, explana-se que ela observou que demoraria um tempo para que alcançasse um cargo gerencial, fato que não a deixava tão motivada, tendo em vista que queria iniciar em um cargo em que pudesse ajudar aos outros e a própria organização.

Em seguida, identifica-se que Roberta apresenta a âncora de Puro Desafio, pois está constantemente buscando por novas experiências, em diferentes áreas, procurando obter o máximo de conhecimento, sem medo de enfrentar novos desafios. Isto pode ser identificado quando há a oportunidade de abrir uma loja de roupas com sua mãe, em que existe o questionamento se Roberta estaria preparada para tal evento e afirma-se que a mesma adorava desafios. Isto também fica evidente quando Roberta opta por deixar seu estágio na empresa $X$, em que teria oportunidade de contratação, para realizar estágio na empresa $Z$, buscando novas experiências. Pode-se destacar também a mudança de área de atuação, quando deixou o estágio em uma instituição pública (empresa Z) para realizar um projeto de iniciação científica com o objetivo de adquirir novos conhecimentos.

Ademais, por possuir um bom relacionamento em grupos e gostar da parte gerencial das organizações, Roberta também apresenta a âncora de Competência Gerência Geral. Esta característica fica evidenciada desde que se apresenta a afirmação de que ela participava de todos os eventos escolares, e o fato de ter sido líder de classe inúmeras vezes no decorrer de sua vida acadêmica. Destaca-se também que Roberta percebeu que desde pequena possuía o dom para liderar, gerenciar, e controlar as pessoas e as situações e que almejava tomar decisões importantes. 
Por fim, a personagem também possui a âncora de Estilo de Vida, ela preza pela união da família e possui um grande vínculo sentimental. Dessa maneira, manter o equilíbrio entre sua vida profissional e familiar é de grande importância para a mesma. É possível visualizar esse perfil de Roberta quando se vê na narrativa do caso a afirmação de que ela sempre morou

próximo aos seus familiares, e por conta disso, possuía um vínculo sentimental muito forte com os mesmos. Ressalta-se também, que ela ficou muito contente ao iniciar o curso de administração em uma universidade na cidade vizinha, pois além de ser o curso desejado, ela estudaria próximo de casa, e estaria próxima a sua família, algo considerado importantíssimo por ela.

Após fazer a análise das âncoras de carreira que Roberta possui, o professor deve orientar que os alunos descrevam quais âncoras eles possuem, explicando o porquê de sua identificação com a mesma.

Questão 3. Quais fatores de empregabilidade Roberta possui e quais precisa desenvolver para seguir os caminhos apresentados no caso?

Nos últimos anos, as organizações passaram por um processo de modificações, em que várias funções foram extintas e novas surgiram, o que resultou na exigência de um maior nível de qualificação e de experiência e na busca de novas habilidades, como flexibilidade, presteza, competência e capacidade para assumir riscos (HETAL, 2005).

Neste cenário, o conceito de empregabilidade se apresenta relevante, pois trata-se das "características individuais do trabalhador, capazes de fazer com que possa escapar do desemprego mantendo sua capacidade de obter um emprego" (LAVINAS, 2001, p. 3). A autora ainda ressalta que essas características podem ser identificadas por meio das competências, habilidades e experiências dos indivíduos.

Para Hetal e Rocha (2011), são inúmeros os fatores que determinam a empregabilidade, sendo que no início de carreira dificilmente os indivíduos possuem todas as habilidades, competências e experiências necessárias, desse modo, é preciso analisar a todo um contexto. No caso de ensino, pode-se observar que Roberta está na 
fase inicial de sua carreira, logo deve-se considerar este fato para a análise de sua empregabilidade.

Há algumas características necessárias para a empregabilidade de pessoas no início de carreira, como: a disposição em apreender novos conhecimentos, a utilização do conhecimento já existente e a realização de tarefas para expandir seu conhecimento e experiência; ademais são necessárias uma supervisão apropriada do trabalho e feedbacks das ações positivas e negativas relacionadas as tarefas desempenhadas (STONE; MORTIMER, 1998).

Considerando a narrativa do caso, observa-se que Roberta possuía poucas experiências no mercado de trabalho, ela trabalhou apenas como estagiária durante sua graduação em três organizações. Com tais experiências, teve a oportunidade de conhecer o funcionamento de uma empresa privada de pequeno e grande de grande porte, assim como, de uma instituição do setor público.

Desse modo, caso opte por seguir carreira em uma empresa privada, Roberta poderia apresentar dificuldades em iniciar em um cargo de alta responsabilidade. Ela deveria optar por iniciar em cargos como assistente ou auxiliar administrativo, assim conseguiria possuir a experiencia necessária para posteriormente se candidatar a cargos gerenciais.

Se Roberta iniciar em uma empresa do segmento em que já atuou, ela teria vantagem, pois possuía experiência sobre o seu funcionamento.

Porém, independentemente da empresa ou cargo, ela precisa mostrar suas competências, conhecimentos e habilidades na execução das tarefas, para manter-se em destaque na empresa e abrir oportunidades futuras.

Destaca-se que geralmente as organizações de grande porte possuem um plano de cargos e salários, em que se busca dar prioridade para o crescimento organizacional de seus funcionários. Sendo assim, se Roberta estiver oferecendo seu melhor poderá crescer na empresa. Mas faz-se necessário avaliar as possibilidades de ascensão e se preparar para as mesmas.

Na carreira pública, Roberta poderia iniciar prestando concursos para o nível do ensino médio, e em seguida, quando fosse formada, prestaria concurso para o nível de graduação, os quais possibilitam a 
ocupação de cargos de níveis gerenciais. Um fator a ser considerado nas organizações públicas é que para sucessão a cargos melhores após a seleção, é necessário aguardar a abertura de um novo edital e de uma nova vaga.

Quanto a alternativa de primeiro fazer o mestrado em Administração, Roberta dispõe de bastante experiência por conta da iniciação científica, sendo assim, possuía algumas habilidades e competências para a execução de trabalhos científicos e acadêmicos para o mestrado, o que poderia auxiliar na sua capacitação para o mercado de trabalho após se tornar mestra. Ela precisaria se preparar para os processos seletivos com o desenvolvimento de pesquisas e publicação das mesmas em periódicos.

Também é importante conhecer o seu potencial na abertura de um empreendimento. Roberta possuía apenas o conhecimento teórico para tal ação, então teria que aprender as habilidades e competências necessárias para a execução eficiente da loja, e teria que adquirir experiência por meio da tentativa e erro.

Questão 4. Se você fosse Roberta, que caminho seguiria? A partir dessa escolha trace o plano de carreira.

Desde os anos 90, a visão sobre o que é carreira vem sofrendo mudanças, a compreensão de que um indivíduo se desenvolvia de maneira dependente de uma organização foi substituída por modelos controlados mais pelas pessoas do que pelas empresas em que trabalham (SILVA, et al., 2016). Os indivíduos precisam gerenciar a si mesmo, para alcançar seus objetivos profissionais, levando em consideração seus valores, habilidades e necessidades (PEÇANHA et al., 2011; COSTA; VIEIRA, 2013).

Nesta perspectiva, as organizações possuem uma função para que o indivíduo alcance com êxito seu objetivo, o plano de carreira é obrigação do indivíduo, mas a gestão de carreira profissional é de responsabilidade da organização, pois é a mesma que oferece oportunidades para que os colaboradores alcancem seus objetivos (PAIXÃO; SILVEIRA, 2017)

Para a definição do plano de carreira a ser seguido por Roberta, primeiro o aluno deverá escolher uma dentre as quatro alternativas evidenciadas no caso. Em seguida, deverá identificar os pontos 
fortes e fracos da opção, e por fim relatar como Roberta pode se preparar para alcançar seu objetivo, enumerando os passos necessários. O quadro 4 apresenta um esboço do que se espera que os alunos identifiquem na resolução da questão.

\section{Quadro 4: Plano de Carreira}

\begin{tabular}{|c|c|c|c|}
\hline $\begin{array}{l}\text { Alternati- } \\
\text { vas }\end{array}$ & Pontos Fortes & Pontos Fracos & Plano de Carreira \\
\hline $\begin{array}{l}\text { Empresa } \\
\text { Privada }\end{array}$ & $\begin{array}{l}\text { - A região da grande Flo- } \\
\text { rianópolis apresenta um } \\
\text { número expressivo de em- } \\
\text { presas de pequeno e médio } \\
\text { porte, em que Roberta pode } \\
\text { iniciar sua carreira profis- } \\
\text { sional. } \\
\text { - Há também um número } \\
\text { considerável de empresas } \\
\text { de grande porte em que ela } \\
\text { pode futuramente alcançar } \\
\text { um cargo estratégico. } \\
\text { - Conhecimento teórico } \\
\text { sobre administração de } \\
\text { empresas. }\end{array}$ & \begin{tabular}{|l|} 
- Pouca ex- \\
periência em em- \\
presas do setor \\
privado. \\
- Não possuir \\
o domínio da \\
língua inglesa. \\
- A concorrência \\
acirrada nos pro- \\
cessos seletivos \\
nas empresas \\
privadas, tendo \\
em vista a quan- \\
tidade expressi- \\
va de formados \\
na área.
\end{tabular} & $\begin{array}{l}\text { 1- Inicialmente tentar } \\
\text { processos seletivos em } \\
\text { empresas de pequeno } \\
\text { e médio porte, para } \\
\text { cargos de assistente e } \\
\text { auxiliar administrativo. } \\
\text { 2- Iniciar um curso de } \\
\text { inglês. } \\
\text { 3- Definir uma área de } \\
\text { atuação e fazer uma } \\
\text { especialização na área. } \\
\text { 4- Buscar ascensão } \\
\text { dentro da empresa } \\
\text { que trabalha ou buscar } \\
\text { novas oportunidades no } \\
\text { mercado de trabalho. }\end{array}$ \\
\hline $\begin{array}{l}\text { Empresa } \\
\text { Pública }\end{array}$ & $\begin{array}{l}\text { - A proximidade da capital } \\
\text { do estado na qual há mui- } \\
\text { tos órgãos públicos. } \\
\text { - Conhecimento teórico a } \\
\text { partir do curso de gradua- } \\
\text { ção, bem como da iniciação } \\
\text { científica. }\end{array}$ & $\begin{array}{l}\text { - Não possuir } \\
\text { conhecimentos } \\
\text { específicos dos } \\
\text { temas abordados } \\
\text { nas provas de } \\
\text { órgãos públicos. } \\
\text { - Não ter finaliza- } \\
\text { do a graduação. } \\
\text { - Não ter condi- } \\
\text { ções financeiras } \\
\text { para dedicar-se } \\
\text { exclusivamente } \\
\text { ao estudo dos } \\
\text { temas abordados } \\
\text { nas provas. }\end{array}$ & $\begin{array}{l}1 \text { - Precisaria iniciar } \\
\text { seus estudos com foco } \\
\text { nos temas abordados } \\
\text { nas provas de órgãos } \\
\text { públicos. } \\
2 \text { - Finalizar a graduação. }\end{array}$ \\
\hline
\end{tabular}




\begin{tabular}{|c|c|c|c|}
\hline Mestrado & $\begin{array}{l}\text { - A região da grande Flo- } \\
\text { rianópolis possui muitas } \\
\text { faculdades, universidade } \\
\text { e centros universitários, } \\
\text { potencializando as opor- } \\
\text { tunidades de empregos no } \\
\text { futuro. } \\
\text { - Não exige experiência } \\
\text { anterior. } \\
\text { - Caso tente o processo } \\
\text { para ingresso no mestrado } \\
\text { na universidade em que faz } \\
\text { sua graduação, a instituição } \\
\text { fica localizada próximo a } \\
\text { sua residência. } \\
\text { - Ter realizado um projeto } \\
\text { de iniciação científica, que } \\
\text { aumenta as chances de } \\
\text { aprovação em processos se- } \\
\text { letivos devido a pontuação } \\
\text { inerente ao mesmo. }\end{array}$ & $\begin{array}{l}\text { - A falta de } \\
\text { publicações na } \\
\text { área, que inter- } \\
\text { fere no resultado } \\
\text { do processo sele- } \\
\text { tivo, bem como } \\
\text { na distribuição } \\
\text { de bolsas. } \\
\text { - Não ter condi- } \\
\text { ções financeiras } \\
\text { para custear o } \\
\text { curso de mestra- } \\
\text { do. } \\
\text { - Não possuir } \\
\text { o domínio da } \\
\text { língua inglesa. }\end{array}$ & $\begin{array}{l}\text { 1- Desenvolver produ- } \\
\text { ções científicas, a fim } \\
\text { de potencializar suas } \\
\text { chances de ingresso no } \\
\text { programa de pós-gra- } \\
\text { duação. } \\
\text { 2- Estudar para as } \\
\text { provas específicas para } \\
\text { ingresso no mestrado. } \\
\text { 3- Participar dos pro- } \\
\text { cessos seletivos em } \\
\text { instituições de ensino } \\
\text { públicas. } \\
\text { 4- Iniciar um curso de } \\
\text { inglês. }\end{array}$ \\
\hline Empresária & $\begin{array}{l}\text { - Conhecimento teórico } \\
\text { sobre administração de } \\
\text { empresas. } \\
\text { - Dispõe do valor necessá- } \\
\text { rio para o investimento. } \\
\text { - Networking e potenciais } \\
\text { clientes. } \\
\text { - Dados iniciais para a } \\
\text { abertura do negócio foram } \\
\text { coletados. } \\
\text { - Lojas de roupas na região } \\
\text { estavam em alta. }\end{array}$ & $\begin{array}{l}\text { - Não possuir } \\
\text { experiência na } \\
\text { gestão de uma } \\
\text { empresa. } \\
\text { - Concorrência } \\
\text { na região. } \\
\text { - Renda familiar } \\
\text { dependerá do } \\
\text { lucro da loja. } \\
\text { - Possíveis con- } \\
\text { flitos familiares. }\end{array}$ & $\begin{array}{l}\text { 1- Buscar conhecimen- } \\
\text { tos sobre a gestão de } \\
\text { lojas de roupas.2- Ana- } \\
\text { lisar viabilidade do } \\
\text { negócio. }\end{array}$ \\
\hline
\end{tabular}

Fonte: Elaborado pelos autores (2019).

Ressalta-se que não há uma alternativa correta e o professor deve avaliar a capacidade dos alunos de elaborar um plano de carreira condizente com a realidade vivida por Roberta. 


\section{BibliogRAFia UTILIZADA}

BERGAMINI, C. W. Motivação: uma Viagem ao Centro do Conceito. GV-executivo, v. 1, n. 2, nov-jan, 2002.

COSTA, L. V.; VIEIRA, A. M. Mãe, não quero ser engenheiro! Dilemas de carreira. Revista Economia \& Gestão, v. 13, n. 31, p. 182-200, 2013.

DRUCKER, P. F. Gerenciando a si mesmo. In: Estratégias para gerenciar sua carreira. Harvard Business Review. Rio de Janeiro: Elsevier, 2003.

FARO, E. S. C et. al. Âncoras de carreira e transformações no modelo de administração: um estudo de caso do Tribunal de Contas (TCU). Cadernos EBAPE BR, Rio de Janeiro, v. 8, n. 4, artigo 9, dez, 2010.

GOMES, et al. Entre âncoras de carreira e a escolha profissional - análise das primeiras definições de carreira dos formandos de curso de administração em São Paulo. Revista Pensamento \& Realidade, v. 26, n.1, 2011.

HETAL, D. H. Flexibilidade organizacional e empregabilidade individual: proposição de um modelo explicativo. Cadernos EBAPE.BR, v. 3, n. 1. mar. 2005.

HETAL, D. H. ROCHA, M. O discurso da empregabilidade: o que pensam a academia e o mundo empresarial. Cadernos EBAPE.BR, Rio de Janeiro, v. 9, n. 1, artigo 8, mar. 2011.

LAVINAS, L. Empregabilidade no Brasil: inflexões de gênero e diferenciais femininos. Rio de Janeiro: Instituto de Pesquisa Econômica Aplicada (IPEA), set. 2001. Disponível em: <http:// repositorio.ipea.gov.br/bitstream/11058/2064/1/TD 826.pdf>. Acesso em: 27 ago. 2017.

MASLOW, A. H. A Theory of Human Motivation. Psychological Review, v. 50, n. 4, p. 37096, 1943.

PAIXÃO, C. R. SILVEIRA, A. O sistema de administração da carreira profissional em uma organização brasileira: destaque no gerenciamento de pessoas. Revista de Carreira e Pessoas, São Paulo, v. 7, n. 01, jan/fev/mar/abr. 2017.

PEÇANHA, L. C. N. et al. Âncoras de Carreira e Relações com Estabilidade e Qualidade de Vida Pessoal: Um Estudo com Alunos do Curso de Gestão de Pessoas. ReCaPE - Revista de Carreiras e Pessoas, São Paulo, v. 1, n. 02, Set/Out/Nov/Dez, 2011.

PÉREZ-RAMOS, J. Motivação no trabalho: abordagens teóricas. Psicologia USP, São Paulo, v. 1, n. 2, p. 127-140, dez. 1990.

SALES, M. L. XAVIER FILHO, J. L. J. DAMASCENA, E. O. Serviço público como expectativa profissional dos graduandos em administração. Revista Pensamento Contemporâneo em Administração, Rio de Janeiro, n. 1. Jan./mar. 2017.

SCHEIN, E. H. Carrrer anchours: discovering your real values. Califórnia: University Associates, 1990.

SILVA, R. C. et. al. Âncoras e valores sob diferentes perspectivas da gestão de carreira. Revista Brasileira de Gestão de Negócios, São Paulo, v. 18, n. 59, p. 145-162, jan/mar. 2016. 
STONE, J. R.; MORTIMER, J. T. The effect of adolescent employment on vocational development: Public and educational policy implications. Journal of Vocational Behavior, v.53, n. 1, p.184-214, 1998.

\section{BIBLIOGRAFIA RECOMENDADA}

BARRETO, D. F. C. et al. Que fatores motivacionais afetam os indivíduos que ingressam em organização do setor público? O caso de uma empresa de energia. Revista GEPROS, n. 4, p. Pag. 11, 2007.

COSTA, A. R.; VIEIRA, A. M. Percepção de sucesso na carreira, bem-estar no trabalho e desempenho: um estudo com professores universitários. Qualit@s (UEPB), v. 16, p. 1-13, 2014.

CHING, H. Y.; KITAHARA, J. R. Propensão a empreender: uma investigação quantitativa baseada nas características empreendedoras de alunos do curso de administração. Revista de Ciências da Administração, v. 1, n. 1, p. 99-111, 2015.

FILIPPIM, E. S. et al. Motivação e Retenção de Docentes em Instituição de Ensino Superior Comunitária. Reuna, v. 23, n. 1, p. 54-74, 2018.

HELAL, D. H.; ROCHA, M. O discurso da empregabilidade: o que pensam a academia e o mundo empresarial. Cadernos EBAPE. BR, v. 9, n. 1, p. 139-154, 2011.

LEMOS, A. H. C.; PINTO, M. C. S. Empregabilidade dos administradores: quais os perfis profissionais demandados pelas empresas?. Cadernos EBAPE. BR, v. 6, n. 4, p. 1-15, 2008.

MOREIRA, S. A. S.; ARAÚJO, B. F. V. B. Homens e Mulheres da Geração Y e suas Âncoras de Carreira. Desenvolvimento em Questão, v. 16, n. 42, p. 621-650, 2018.

SALES, M. L.; XAVIER FILHO, J. L. J.; DAMASCENA, E. O. Serviço Público como expectativa profissional dos graduandos em administração. Revista Pensamento Contemporâneo em Administração, v. 11, n. 1, 2017.

SILVA, R. C. et al. Âncoras e valores sob diferentes perspectivas da gestão de carreira. Revista Brasileira de Gestão de Negócios, v. 18, n. 59, p. 145-162, 2016.

SOUZA, R. A. et al. Identidade com a Carreira: a perspectiva de acadêmicos em relação ao desenvolvimento da vida profissional. Revista de Administração, Sociedade e Inovação, v. 2, n. 2, p. 90-105, 2016.

Recebido em: 14-2-2018

Aprovado em: 1-6-2019

Avaliado pelo sistema double blind review.

Editor: Coordenação do PPGA/UMESP

Disponível em http://mjs.metodista.br/index.php/roc 